\title{
Optimizing growth of conifer seedlings in vitro
}

\author{
G. Flygh, R. Grönroos and S. von Arnold
}

Department of Forest Genetics, The Swedish University of Agricultural Sciences, Box 7027, S-750 o7 Uppsala, Sweden

The aim of this work was to determine which culture parameters limit growth of conifers under in vitro conditions.

\section{Materials and Methods}

Seeds of Pinus sylvestris and $P$. contorta were used. After surface sterilization the seeds were sown in glass jars. If not otherwise stateú, $800 \mathrm{ml}$ giass jars containing a sierile mixture of $300 \mathrm{ml}$ of vermiculite and $200 \mathrm{ml}$ of $25 \%$ ingestad nutrient solution (Ingestad, 1979) were used. The $\mathrm{pH}$ was adjusted to 5.9 before autoclaving. Thirty seeds were sown in each jar. The jars were sealed with plastic foil and incubated in a growth cabinet at $20^{\circ} \mathrm{C}$ under continuous light $\left(165 \mu \mathrm{E} \cdot \mathrm{m}^{-2} \cdot \mathrm{s}^{-1}\right)$.

The effect of aeration on seedling growth (fresh and dry weight and general morphology) was tested by supplying the jars with a contin- uous flow of air with atmospheric or raised $\mathrm{CO}_{2}$ concentrations. The $\mathrm{CO}_{2}$ concentration in the jars was analyzed by gas chromatography after various times.

The influence of vermiculite, autoclaving and seed germination on $\mathrm{pH}$ and nitrogen content in the culture medium was tested in a series of experiments. The liquid fraction was separated from the vermiculite before analyses.

\section{Results and Conclusion}

\section{Aeration and $\mathrm{CO}_{2}$ concentrations}

The increase in dry weight from d 18 to 46 was $125 \%$ when seedlings of $P$. contorta were cultured in aerated jars but only $40 \%$ in the control (Figs. 1, 2). Root growth and

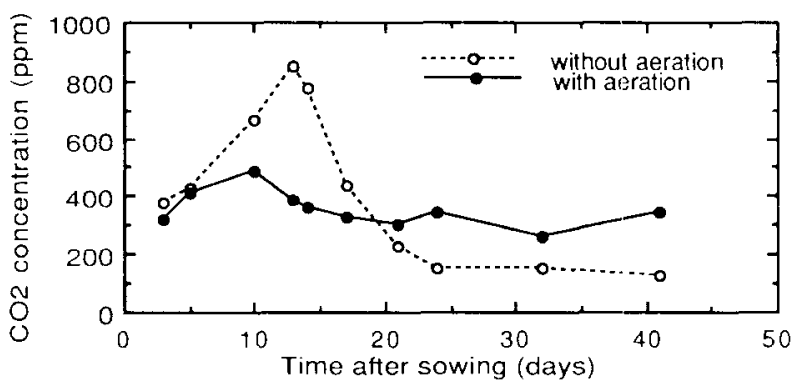

Fig. 1. $\mathrm{CO}_{2}$ concentration in glass jars with $P$. contorta seedlings with and without continuous aeration. Each point represents the average of 3 jars. 


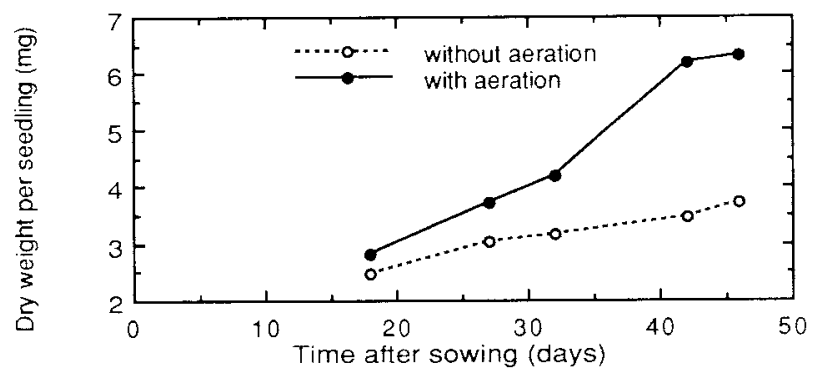

Fig. 2. Dry weight of $P$. contorta seedlings after culture in glass jars with and without continuous aeration. Each point represents the average dry weight per seedling based on about 50 seedlings (= all seedlings in 2 jars). The whole experiment included 20 jars.
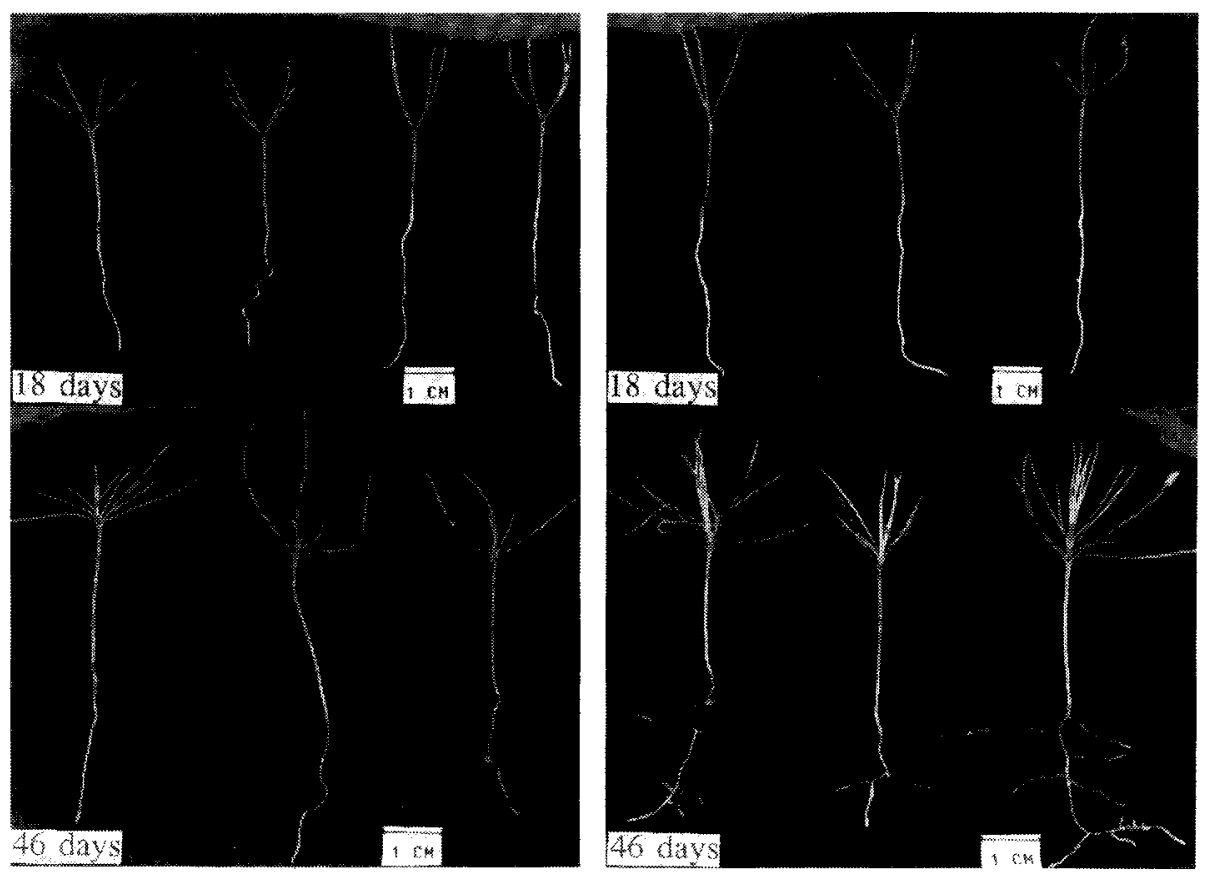

Fig. 3. Seedlings of $P$. contorta cultured in vitro with and without aeration.

branching were stimulated by aeration (Fig. 3). A similar stimulation of growth by aeration was obtained with $P$. sylvestris. In another series of experiments, the importance of $\mathrm{CO}_{2}$ concentrations in the air flow was tested with $P$. sylvestris (Fig. 4). The results indicated that the $\mathrm{CO}_{2}$ concentration in the air flow was not critical in the range of $360-7000 \mathrm{ppm}$. Aeration of the culture vessel stimulated growth in vitro. 


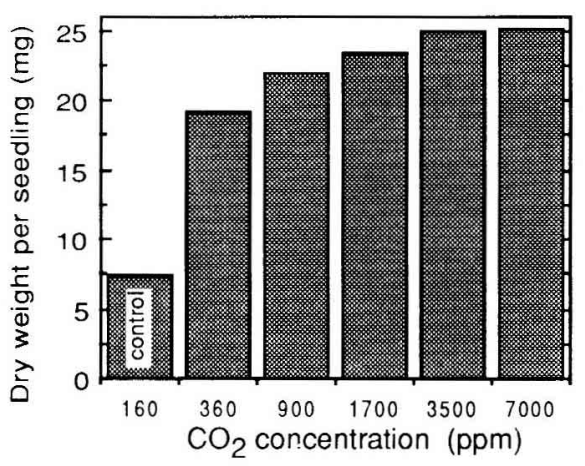

Fig. 4. Dry weight of $P$. sylvestris seedlings cultured for $24 \mathrm{~d}$ with various $\mathrm{CO}_{2}$ concentrations. The dry weight present in each column is an average of 30 seedlings. Control seedlings were cultured without continuous aeration.

\section{Nitrogen content}

Vermiculite had a drastic effect upon ammonium content and $\mathrm{pH}$ in the culture medium (Tables I and II). Therefore, it was not possible to perform detailed studies of nitrogen uptake and $\mathrm{pH}$ changes during growth in verrniculite. After the seedlings had been cultured for $45 \mathrm{~d}$, the medium still contained ammonium and nitrate. No differences were observed in nitrogen concentration whether or not the jars had been aerated, although the seedlings grew much better in aerated jars. Hence, nitrogen was not the limiting factor for growth.

Table I. $\mathrm{pH}$ changes in the culture medium with verrniculite.

\begin{tabular}{llll}
\hline Initial pH & 4.0 & 5.9 & 7.0 \\
$\mathrm{pH}$ after autoclaving & 4.0 & 5.9 & 7.0 \\
$\mathrm{pH}$ after 1 $\mathrm{h}$ with vermiculite & 7.8 & 7.8 & 7.8 \\
$\mathrm{pH}$ after 45 $\mathrm{d}$ with vermiculite & & $6.5-7.5$ & \\
\hline
\end{tabular}

The $\mathrm{pH}$ was adjusted to $4.0,5.9$ or 7.0 before autoclaving. Seeds of $P$.

Table II. Nitrogen content of the culture medium after germination.

\begin{tabular}{lll}
\hline Liquid medium & $\begin{array}{l}\mathrm{N}-\mathrm{NH}_{4} \\
(\mathrm{mg} / \mathrm{l})\end{array}$ & $\begin{array}{l}\mathrm{N}-\mathrm{NO}_{3} \\
(\mathrm{mg} /)^{\prime}\end{array}$ \\
\hline After autoclaving & 29.2 & 34.2 \\
1 d after mixture with vermiculite & 7.9 & 36.8 \\
12 d after sowing & 6.4 & 28.4 \\
$19 \mathrm{~d}$ after sowing & 5.2 & 31.0 \\
$45 \mathrm{~d}$ after sowing & 4.3 & 33.5 \\
\hline
\end{tabular}

30 seeds of $P$. contorta were cultured in each jar conteining $160 \mathrm{ml}$ of nutrient medium mixed with $360 \mathrm{ml}$ of vermiculite.

\section{References}

Ingestad T. (1979) Mineral nutrient requirements of Pinus sylvestris and Picea abies seedlings. Physiol. Plant. 45, 373-380 